\title{
Research of Loess Dynamic Subsidence under Locomotive Vibration Load of the High-speed Railway
}

\author{
Tao Yang, Jiading Wang, Huilai Luo, Qiang Li \\ State Key Laboratory of Continental Dynamic, Department of Geology, Northwest University, Xi'an, 710069, China \\ Shijiazhuang University of Economics, Shijiazhuang, 050031, China \\ The first of Geology and Mineral Exploration Institute of Shandong Province, Jinan, 250014, China
}

\begin{abstract}
This paper discusses a problem that loess dynamic settlement occurs and changes lager under locomotive vibration load during the high speed railway is running. In order to solve the problem efficiently, we firstly do a group of experiments about dynamic triaxial test of loess. This method does not require measuring on site and can get easily some precise parameters in the laboratory. Then the numerical model is proposed to calculate simply loess dynamic subsidence on the base of experiments, the way is used to measure according to layerwise summation method. Finally, the settlement prediction on the high-speed railway is effective and feasible to a certain extent in the actual use.
\end{abstract}

Keywords-dynamic triaxial test; settlement; high-speed railway; vibration load.

\section{INTRODUCTION}

With the development of economy and technology, high speed railway has the greater proportion in the traffic enterprise in our country. It is one type of daily transportation that is getting more and more convenient and safe, and it will make rapid progress with its own advantages. Because high-speed railway is increasingly popular today and the speed of passenger vehicle is getting faster, the higher demand on the foundation of high-speed railway needs to be satisfied. There are a series of problems caused by high speed that more and more people pay attention to and some experts has made some theoretical results on the aspect, for example, the acceleration and the displacement of subgrade vibration are calculated by Zhihong Nie under train load with different ballast thickness and stiffness ${ }^{[1]}$; the foundation deformation characteristics is researched by Changjing Wang and Yunmin Chen through dynamic triaxial test of soil under traffic loads ${ }^{[2]}$; Yiqun Tang etc. simplified train load as a continuous sinusoidal load with $0.5 \mathrm{~Hz} \sim 2 \mathrm{~Hz}$ and through dynamic three triaxial tests, they studied the effect on on critical dynamic soil stress and dynamic strain of subway tunnel under vibration $\operatorname{load}^{[3 \& 4]}$. However, the study of foundation deformation is less in the aspect of multi vibration times and multi cycles under vibration load of high-speed train. This paper is researched on the base of the test of undisturbed soil sample along high-speed railway in the virtue of the GDS apparatus of dynamic triaxial test, foundation subsidence is analyzed and estimated under locomotive dynamic effect and the prediction and the evaluation of vibration loads is proposed.

\section{TEST INSTRUMENT}

The soil tests of dynamic property are performed on the GDS high system of dynamic triaxial test imported from the UK, this test system can make axial load of arbitrary waveform applied directly to the specimen through the up and down motion of loading piston (Figure.1).

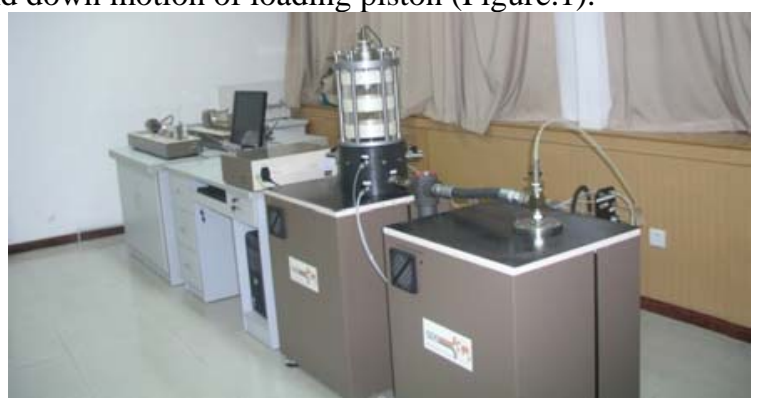

Figure 1. British GDS advanced system of dynamic triaxial test

Before the experiment, a random set of locomotive data of dynamic load with time change is used and changed into the numerical simulation conversion in microcomputer, electrical signals converted and simulated are recorded on the magnetic tape. During the experiment, simulation signals recorded on the tape are reproduced, the output amplitude controller can adjust the amplitude of output signal from tape recorder, simulation signal wave with some amplitude is made power amplifier through the power amplifier instrument, it is directly input to the electromagnetic coil of dynamic triaxial apparatus and electric signal is converted to the change of magnetic force that push the loading piston and control the up and down motion. Thus the seismic wave are applied directly to the sample, its main technical parameters are shown that the maximum amplitude of $1 \mathrm{~Hz}$ is $14 \mathrm{~mm}$, the maximum vibration frequency is $5 \mathrm{~Hz}$, the largest axial pressure is $64 \mathrm{kN}$, the range of axial displacement is $0 \mathrm{~mm} \sim 90 \mathrm{~mm}$, and the simple size is from $50 \mathrm{~mm} * 100 \mathrm{~mm}$ to $150 \mathrm{~mm} * 300 \mathrm{~mm}$. 


\section{TEST PROCEDURES AND RESULTS}

\section{A. Sample preparation}

The samples are prepared by using on-situ undisturbed soil; they are cut into the standard size that is diameter of $50 \mathrm{~mm}$ and height of $100 \mathrm{~mm}$. Moisture content and bulk density need to be determined firstly, in order to make sure moisture content correctly, the soil should be taken close to the sample when the cutting residual soil is used.

The undisturbed soil samples are taken around Tongguan along the high-speed railway from Zhengzhou to $\mathrm{Xi}$ 'an, the sample depth range is from ground to underground $5 \mathrm{~m}$, a soil sample is taken every one meter and the total number of samples is 23 .

\section{B. Sample installation}

The first step is that rubber membrane is set in the mould bearing cylinder and the rubber membrane can be pressed close to the inner wall of the mould cylinder by the sucking ball suction. Secondly, the sample is put easily in the mould bearing cylinder, the rubber membrane is close to the sample at this time of the sucking ball removed. Permeable stones are placed on the top and the bottom of the sample, filter papers are placed between permeable stone and the sample. The loading base need to be adjusted down to the initial position before sample installation and then rubber membrane is fixed the sample cap and the base with the help of the $\mathrm{O}$ ring. Thirdly, the confining pressure chamber and the base are fixed firmly by the bolts; the oil inlet valve and the oil pump of the confining pressure chamber are opened. At last, when oil overflows the confining pressure chamber, we should close the oil inlet valve of the confining pressure chamber before turning off oil pump and finally close the confining pressure chamber. The contact pressure between the specimen cap and loading head is $0.0 \mathrm{kN}$ by moving up the loading base.

\section{Sample compression}

Sample confining pressure is set to two grades: $50 \mathrm{kPa}$ and $100 \mathrm{kPa}$. According to the stress characteristics of subgrade along high-speed railway under the locomotive load and dynamic stress size, the numerical axial compression is determined by the formula that is shown as below:

$$
\sigma_{1 C}=\sigma_{3 C}+\sigma_{d}
$$

\section{Sample loading}

After the deformation is stable under confining pressure applied, the dynamic axial load is applied. The loading standard is stress control and the loading waveform is sine wave, the control frequency of dynamic axial stress loading is $1 \mathrm{~Hz}$. The vibration center of dynamic load is $\sigma_{3 C}+\sigma_{d}$. Before the official loading, the stiffness coefficient can be estimated by setting a small dynamic stress and dynamic stress size and different power amplitude are corresponded. When the amplitude of dynamic load for design are respectively $0.1 \mathrm{kN}, \quad 0.2 \mathrm{kN}, \quad 0.3 \mathrm{kN}$ and $0.4 \mathrm{kN}$, the corresponding dynamic stress are $51 \mathrm{kPa}, 102 \mathrm{kPa}, 153 \mathrm{kPa}$ and $204 \mathrm{kPa}$.

\section{E. Test results}

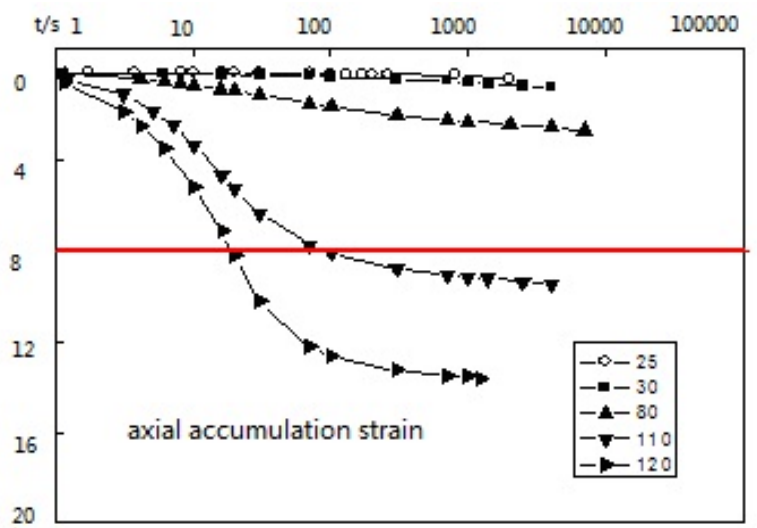

Figure 2. Axial accumulation strain curve of $50 \mathrm{kPa}$ confining pressure

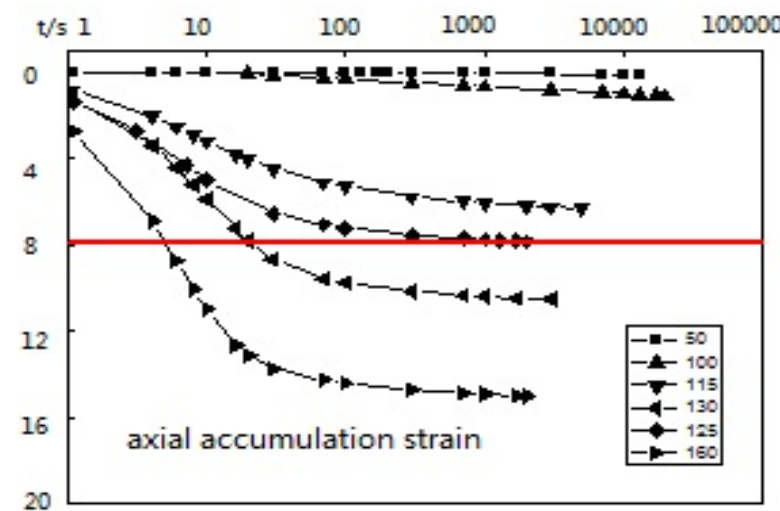

Figure 3. Axial accumulation strain curve of $100 \mathrm{kPa}$ confining pressure

\section{THE CALCULATION AND PREDICTION SIMPLIFIED OF SEISMIC SUBSIDENCE}

According to dynamic model test of the slab ballastless track, power attenuation formula can be obtained and used to calculate dynamic stress value at each depth of subgrade. Then the formula of dynamic stress-strain relationship can calculate the depth of roadbed strain value by using the triaxial strain test every vibration. Finally adopting layerwise summation method, we can get the foundation summation settlement.

Based on the dynamic model test of the slab ballastless track, test data of power decay is shown that the attenuation coefficient is accordingly $1,0.77,0.63,0.48,0.35,0.15$, $0.04,0$, when the depth is $0 \mathrm{~m}, 0.4 \mathrm{~m}, 0.7 \mathrm{~m}, 1.1 \mathrm{~m}, 1.6 \mathrm{~m}, 3 \mathrm{~m}$, $5 \mathrm{~m}, 7 \mathrm{~m}$. We can get the power attenuation curve formula by fitting attenuation curve data of slab ballast track test from dynamic stress along the depth of the subgrade, and the formula is shown as below.

$$
\lambda=0.97 \mathrm{e}^{\frac{-H}{1.13}}+0.013
$$


In the formula: $\lambda$ represents the attenuation coefficient, $H$ represents the subgrade depth.

Based on the relationship between dynamic stress and dynamic strain of the dynamic triaxial test curve with various vibration times, we can get the relation formula of dynamic stress and dynamic strain.

TABLE I. RELATION DATA OF THE DYNAMIC STRESS AND STRAIN EVERY VIBRATION TIME

\begin{tabular}{cccccc}
\hline Dynamic & \multicolumn{5}{c}{ The number of vibrations } \\
\cline { 2 - 6 } stress & 200 & 500 & 1000 & 2000 & 4000 \\
30 & $0.35 \%$ & $0.44 \%$ & $0.55 \%$ & $0.65 \%$ & $0.74 \%$ \\
80 & $1.80 \%$ & $2.10 \%$ & $2.26 \%$ & $2.29 \%$ & $2.53 \%$ \\
110 & $8.35 \%$ & $8.90 \%$ & $9.13 \%$ & $9.33 \%$ & $9.46 \%$ \\
120 & $12.94 \%$ & $13.43 \%$ & $13.57 \%$ & $13.59 \%$ & $13.59 \%$ \\
\hline
\end{tabular}

If the number of vibration is 200 ,

$$
\varepsilon_{d}=0.046 \mathrm{e}^{\frac{\sigma_{\mathrm{d}}}{21.27}}+0.043 \text {; }
$$

If the number of vibration is 500 ,

$$
\varepsilon_{d}=0.063 \mathrm{e}^{\frac{\sigma_{\mathrm{d}}}{22.39}}+0.081
$$

If the number of vibration is 1000 ,

$$
\varepsilon_{d}=0.071 \mathrm{e}^{\frac{\sigma_{\mathrm{d}}}{22.88}}+0.156
$$

If the number of vibration is 2000 ,

$$
\varepsilon_{d}=0.078 \mathrm{e}^{\frac{\sigma_{\mathrm{d}}}{23.26}}+0.202 \text {; }
$$

If the number of vibration is 4000 ,

$$
\varepsilon_{d}=0.092 \mathrm{e}^{\frac{\sigma_{\mathrm{d}}}{24.083}}+0.272
$$

The predict long-term settlement can be predicated according to the settlement numerical simulation and the relation of settlement and subgrade vibration times for above different vibration times.

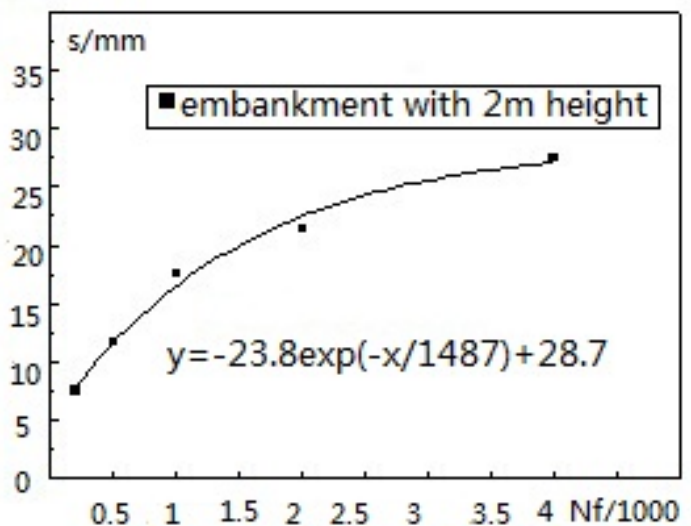

Figure 4. The settlement prediction curve of embankment with $2 \mathrm{~m}$ height

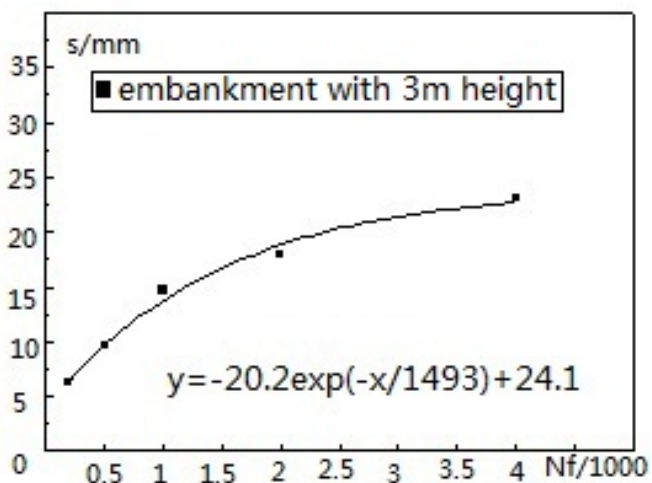

Figure 5. The settlement prediction curve of embankment with $3 \mathrm{~m}$ height

From the settlement prediction plot, we can see that the settlement decreases with the depth increasing at the same condition of vibration times. When the condition is different vibration tomes, settlement increases with the increase of vibration times and gradually keeps stable. According to the degree of impact on foundation damage of the building, the provisions are formulated and named as the grade standards of foundation damage. When the quantity of seismic subsidence is less than 2cm, foundation is basically intact, when the quantity of seismic settlement is in $2 \mathrm{~cm} \sim 4 \mathrm{~cm}$, the damage is slight. When the quantity of seismic subsidence is in $4 \mathrm{~cm} \sim 8 \mathrm{~cm}$, it belongs to medium damage.

\section{CONCLUSIONS}

This paper puts forward a simplified calculation method for the vibration settlement under locomotive load and the settlement is forecasted according to the prediction curve of subsidence. There are some changes in the settlement of subgrade loess under vibration load of locomotive. When the embankment height is respectively $2 \mathrm{~m}$ and $3 \mathrm{~m}$, the settlement of loess subgrade is about $0.8 \mathrm{~cm}$ and $0.6 \mathrm{~cm}$ at the vibration times of 200 . When the amount of vibration times is gradually increased to 4000 , the settlement is about $2.7 \mathrm{~cm}$ and $2.3 \mathrm{~cm}$. Therefore, at the same vibration times, the loess foundation settlement increases with embankment height decreasing. At the same height of embankment under different vibration times, the foundation settlement of loess increases and gradually keeps stable with the increase of vibration time

\section{ACKNOWLEDGEMENTS}

This research is jointly supported by National Natural Science Foundation of China(41372269), Hebei Science and Technology Program (13275410) and Foundation of He'bei Educational Committee(Z2013125).

\section{REFERENCES}

[1] NIE Zhihong,RUAN Bo, LI Liang. Dynamic analysis of subgrade of high-speed railway in geometric irregular condition[J]. Journal of the China Railway Society,21(2),pp.84-88,1999.

[2] WANG Changjing, CHEN Yunmin. Study on effect of traffic loading induced static deviator stress on undrained cyclic properties of saturated soft clay [J]. Chinese Journal of Geotechnical Engineering, 29(11), pp. 1742-1747,2007. 
[3] TANG Yiqun, HUANG Yu, YE Weimin, etal. Critical dynamic stress ratio and dynamic strain analysis of soils around the tunel under subway train loading [J].Chinese Journal of Rock Mechnics and Engineering, 22(9), pp.1566-1570,2003.
[4] TANG Yiqun, ZHANG Xi, YE Weimin, etal., A study on dynamic strength and dynamic stress-strain relation of silt under traffic loading[J]. Journal of Engineering Geology,12(1),pp.983-101,2004. 